\title{
Platform bone switch to increase cervical ring bone mass
}

\author{
Ole Jensen $^{1}$, Georgios Romanos ${ }^{2}$, Paul Glick ${ }^{3}$ \\ ${ }^{1}$ School of Dentistry, University of Utah, Salt Lake City, UT, USA; ${ }^{2}$ Department Periodontology, Director and Founder of Laboratory of \\ Periodontology, Director for LASER Education at SDM, CMLSO, Stony Brook University, School of Dental Medicine, Stony Brook, NY, USA; \\ ${ }^{3}$ Private Practice Periodontology, Aspen, Corona, CA, USA \\ Contributions: (I) Conception and design: O Jensen; (II) Administrative support: P Glick; (III) Provision of study materials or patients: O Jensen; (IV) \\ Collection and assembly of data: O Jensen; (V) Data analysis and interpretation: O Jensen, G Romanos; (VI) Manuscript writing: All authors; (VII) \\ Final approval of manuscript: All authors. \\ Correspondence to: Ole Jensen. Department of Oral Maxillofacial Surgery, University of Utah, School of Dentistry, Salt Lake City, UT 84108 , USA. \\ Email: oletjensen2526@gmail.com.
}

\begin{abstract}
A tapered straight-wall implant and a reverse conical neck implant were compared at the cervical margin in terms of bone volume of the ring of bone showing long term clinical application. One reverse conical neck implant, the reverse concave neck implant, showed a substantial difference in ring of bone volume with an increase of $5.57 \mathrm{~mm}$ when compared to a straight-wall implant. Favorable strategies at the cervical crestal two millimeters include narrowing of the neck, the so called conical neck, reverse concave neck and multiple cervical grooves all of which add incrementally to preserve dense crestal bone. The importance of cervical ring of bone mass is often unnoticed but becomes highly important in compromised, tight interdental spaces such as a $6 \mathrm{~mm}$ diameter space or in a setting where buccal bone is thin or lost leading to implant surface exposure because of loss of integrity of the ring of bone. One cannot always make corrections for dehiscence in the ring of bone by bone grafting such as is done facially, particularly when the dehiscence may go unnoticed or develop soon after implant placement interrupting the continuity of protective crestal bone. Though a tooth root may do adequately with as little as $1 \mathrm{~mm}$ of bone coverage an implant needs more, such as $2 \mathrm{~mm}$ or more, to buttress against bacterial insult and other potential resorptive stresses. An overall increase in bone volume due to a platform bone switch leads to greater cervical bone mass as a starting point for osseointegration maintenance. These findings also suggest that this greater bone mass for maintaining adequate bone at the margin of the implant which if otherwise lost could lead to periimplantitis.
\end{abstract}

Keywords: Platform bone switch; platform switch; ring of bone; cervical bone; peri-implant disease; periimplantitis; abutments

Received: 03 June 2021; Accepted: 29 October 2021; Published online: 30 November 2021.

doi: $10.21037 /$ fomm-21-72

View this article at: https://dx.doi.org/10.21037/fomm-21-72

The supporting bone at the alveolar crest around a margin of a dental implant has been termed by Danza to be the "ring of bone" (Figure 1A). This cervical ring of bone shown schematically in an occlusal view around a titanium implant in Figure $1 B$ is the first line of defense in the prevention of gingival recession and exposure of titanium potentially leading to peri-implant disease (1).

When cervical bone mass is thin, especially in the maxillary anterior, such as less than $1.8 \mathrm{~mm}$ as found in one study, or if the ring of bone is discontinuous or interrupted, such as is sometimes found with angled implant placement, access to the body of the implant is more easily obtained by constituents of oral biofilm. Whereas, as long as bone is present up to platform level, particularly if there is healthy and adequate quantity of bone, the "gateway" to periimplant disease is closed (2).

Mesiodistal and palato-facial aspects of the ring of bone are both important-the mesiodistal bone mass for 

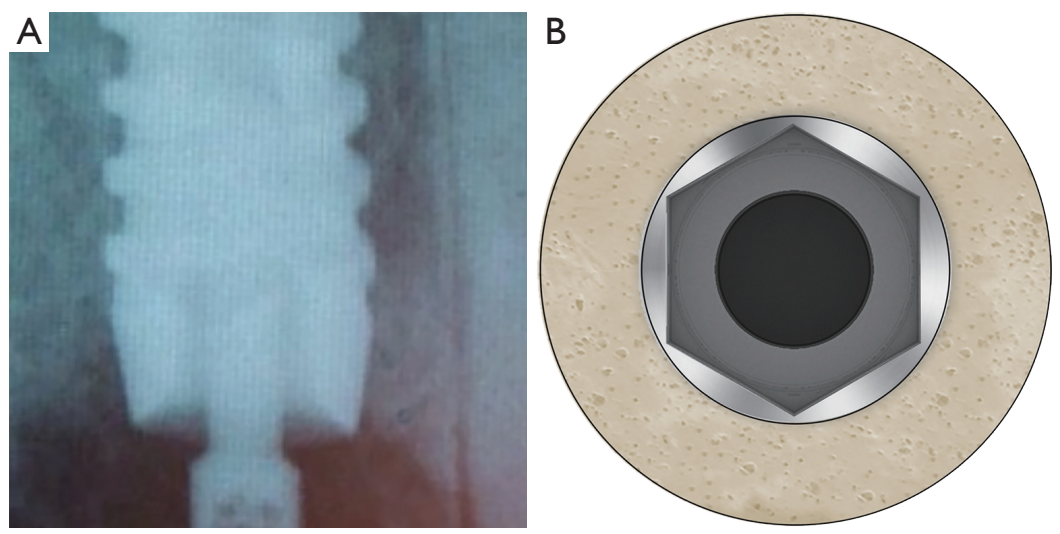

Figure 1 Lateral and occlusal view of cervical bone around an implant, suggesting the primary importance of ring of bone mass. (A) An $\mathrm{X}$-ray view of crestal bone support at the conical neck showing the crestal most two mm of bone support surrounding a dental implant. The ring of bone is vertically taller mesio-distally when next to teeth as subpapillary bone projection is higher. The ring of bone is generally most compromised buccally where dehiscence is frequently found requiring bone augmentation grafting. (B) Figure shows a schematic of the implant in occlusal view with the ring of bone uniformly surrounding an implant.
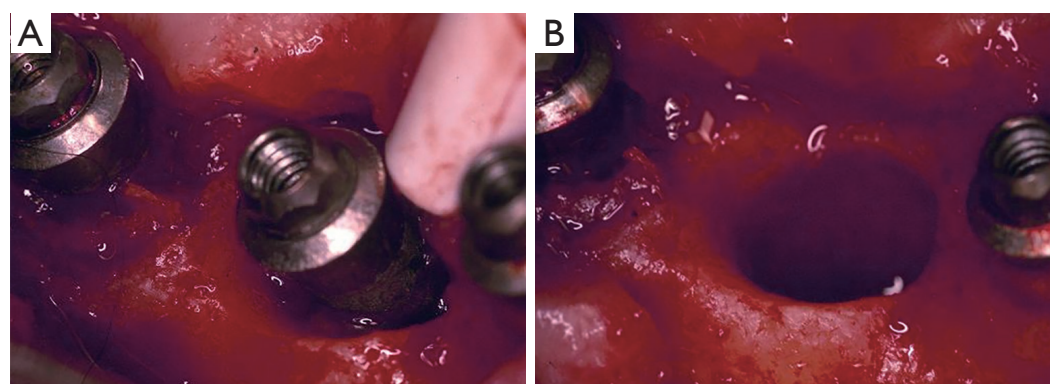

Figure 2 When the ring of bone is lost, typical circumferential lesions occur can progress to loss of the implant as shown clinically above. (A) An implant had developed circumferential peri-implant disease with deep pocketing and bone loss. (B) The implant was removed as a salvage procedure to recover osseointegration was not possible (Courtesy of Dr. Dennis Tarnow, Columbia University with permission).

subpapillary bone support and the palato-facial for marginal gingival integrity. The ring of bone also becomes especially important in proximate implant settings, proximate tooth situations and at times in off-axis placement. When the ring of bone is lost, typical circumferential lesions occur can progress to loss of the implant as shown clinically in Figure $2 A, 2 B(3,4)$.

The so-called platform switch of the hardware connection of the abutment and implant body can lead to more inter-proximal bone and therefore an increased bone mass for the ring of bone as shown in Figure $3 \mathrm{~A}, 3 \mathrm{~B}$ schematically for a straight wall implant. "Platform bone switch", a separate idea, is a function of narrowing of the neck of the implant using a design of a "reverse conical neck", which potentially adds an additional quantity of interproximal bone (Figure 3C) being additive to the abutment connection platform switch as illustrated in Figure $3 D$ and shown clinically in Figure $3 E, 3 F(5,6)$.

Several implant manufacturers have recognized the benefit of narrowing the neck of the implant as seen in Figure $4 A-4 D$ but the vast majority of implants placed are straight-walled and often tapering outward, getting wider at the alveolar crest, possibly impacting ring of bone continuity.

Post orthodontic patients who have lost bone volume secondary to tooth movement can maintain teeth for years with minimal or even absence of facial bone because of adequate thickness of fixed gingival attachment coupled with excellent oral hygiene. In dental implant settings 

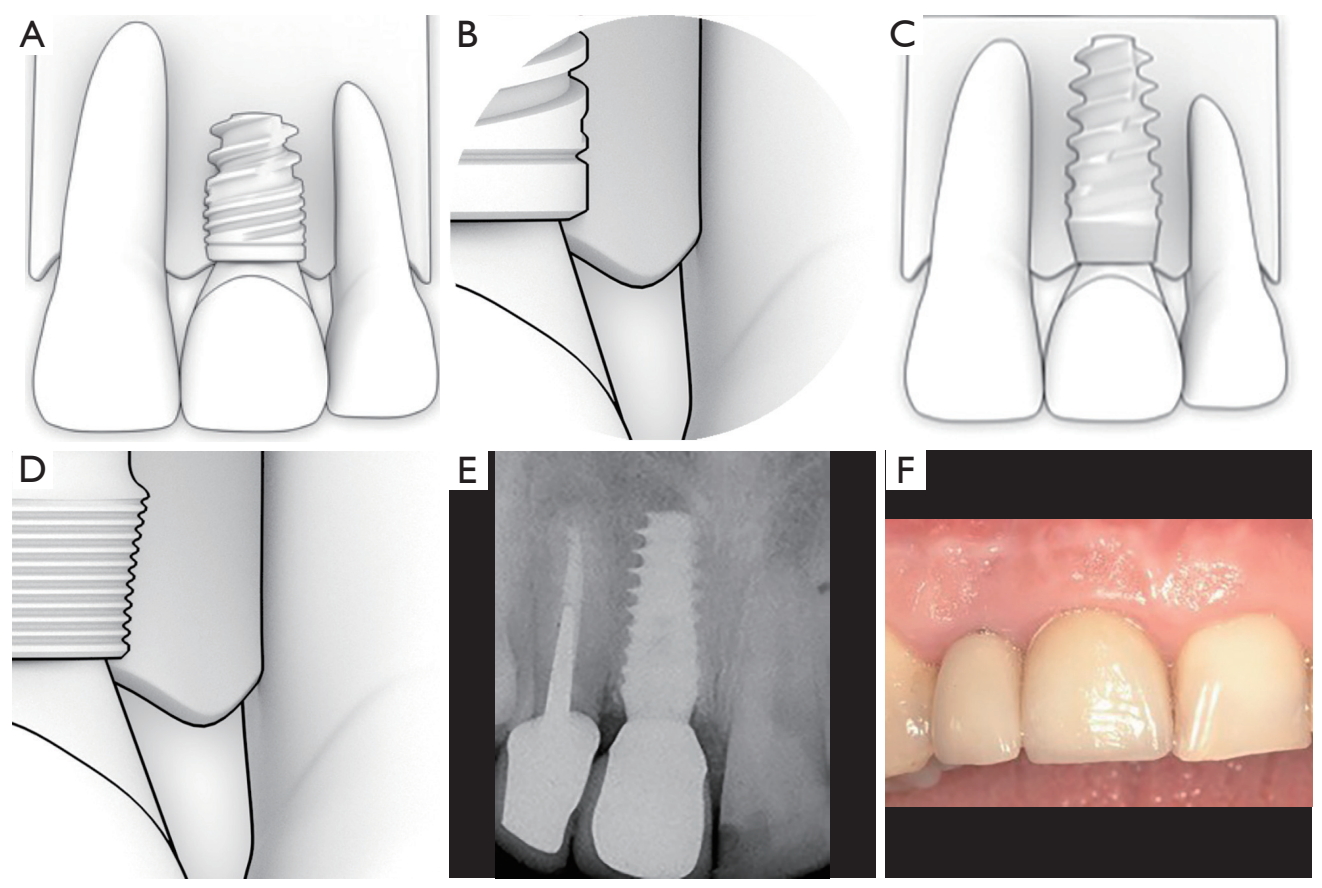

Figure 3 The schematic difference of platform switch, hardware phenomenon, platform bone switch, and biological phenomenon. (A,B) Schematically illustrated the platform switch in a straight-wall implant, a hardware mismatch of the abutment to the implant platform where the abutment is inset approximately $0.5 \mathrm{~mm}$. (C,D) The "platform bone switch", a separate concept, is a narrowing of the neck of the implant termed the reverse conical neck. Both platform switch and platform bone switch were served to preserve bone around the neck of a dental implant. (E,F) The addition of the platform bone switch to the platform switch is shown in the post restoration X-ray above where the implant is placed too close to the adjacent lateral incisor tooth related to immediate extraction anatomy forcing the drilling sequence toward the adjacent tooth root such that the implant is now placed less than $2 \mathrm{~mm}$ away. However, because of the reverse conical neck, additional space is provided for bone at the alveolar crest so that a blunted distal papilla, though compromised, is still able to form.

however, a dehiscence is a significant risk factor that can lead to loss of soft tissue attachment and progression to peri-implant disease. These patients who present with discontinuity of the ring of bone must be augmented facially at the time of implant installation to insure $2 \mathrm{~mm}$ or more of facial bone thickness. In fact, one rationale for placement of the implant into the palatal side of an extraction socket is to allow for development of more facial bone mass in an effort to maintain bone height and width for marginal gingival stability $(7,8)$.

One additional concept introduced in the literature is to place implants slightly subcrestally which was shown in one study to lead to stable peri-implant bone $(9,10)$.

The purpose of this paper is to present peri-implant bone volumetric findings (mathematically) relative to implants in the cervical area that have two different geometries supported by clinical report. The two implant shapes are made by the same manufacturer (Ditron Ltd, Ashkelon,
Israel), have the same $4.2 \mathrm{~mm}$ diameter, with one implant being a straight-walled (tapered) implant, versus a reverse conical neck implant as shown in Figure 5A,5B.

The hypothesis question posits a compromised site of $6 \mathrm{~mm}$ diameter, in which for biomechanical reasons a $4.2 \mathrm{~mm}$ diameter implant is preferred-the question being: Is there a substantial difference in ring of bone preservation between the two implant types?

The factors studied are:

(I) Horizontal thickness of cervical bone ring.

(II) Bone mass support for adjacent papilla proximate to a tooth.

(III) Bone mass support for adjacent papilla proximate to another implant.

(IV) Total bone mass volume difference in $\mathrm{mm} 3$ for the crestal vertical $2 \mathrm{~mm}$ determined for the two implant types.

(V) Abutment-Implant interface factor. 

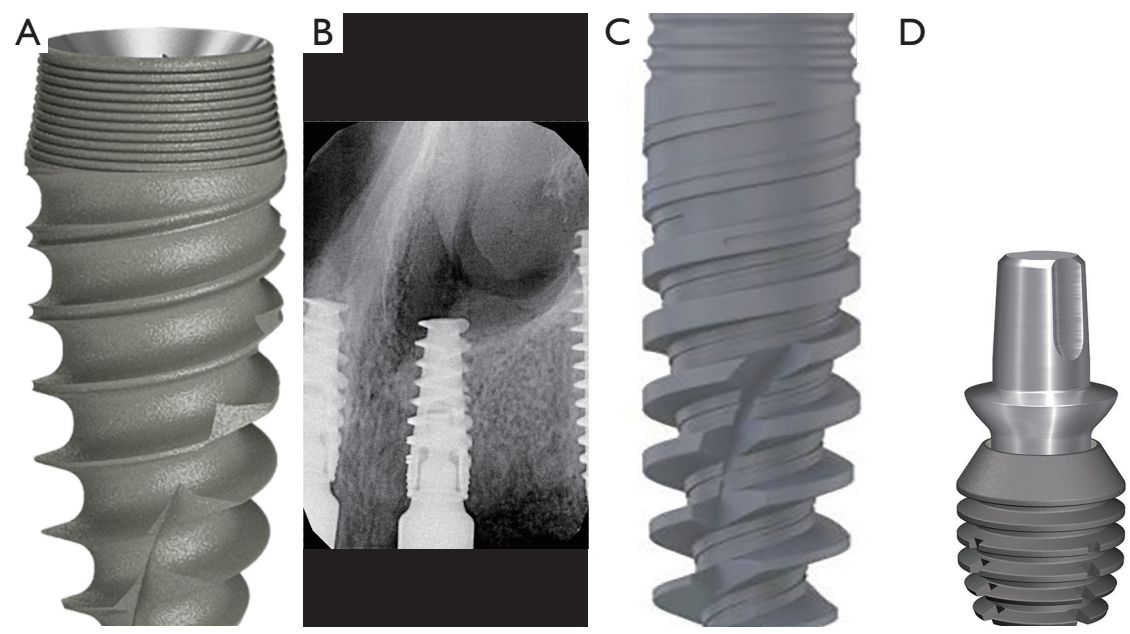

Figure 4 Several dental implant manufacturers have made implants with narrower necks as shown above: (A) the Ditron Ultimate implant (Ditron Ltd. Ashkelon, Israel with permission); (B) the Nobel Active implant (Nobelbiocare, Inc. Kloten, Switzerland with permission); (C) the DSI conical design (Dental Solutions Israel Ltd. Ashdod, Israel with permission); (D) the Bicon implant (Bicon Inc. Boston, Mass with permission).

A

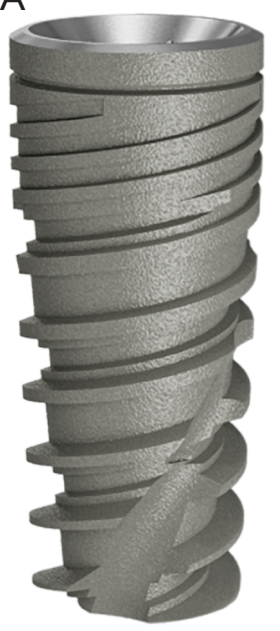

B

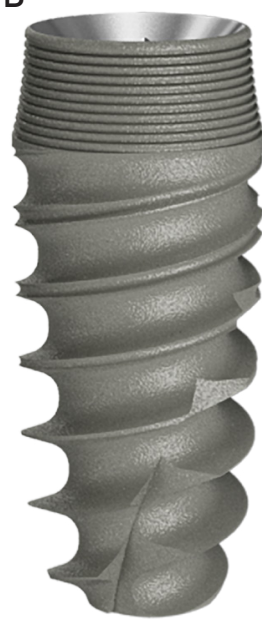

Figure 5 Two $4.2 \mathrm{~mm}$ diameter implant designs (Ditron Dental Ltd. Ashkelon, Israel with permission) were compared in a bone limited site of $6 \mathrm{~mm}$ diameter to assess bone volume preservation at the crest by the two implants especially when proximate to teeth and other dental implants. A straight wall implant (A) and a reverse conical neck implant (B) were selected to compare. The comparative study is meant to address the ring of bone compromise by titanium elements that might lead to gingival recession and/or exposure of titanium surface to increase the risk for periimplantitis.

\section{Horizontal thickness of cervical ring}

The thickness of peri-implant bone around an implant optimally should be greater than $1 \mathrm{~mm}$ with $2 \mathrm{~mm}$ or greater bone thickness being most ideal. However, in the anterior maxilla that would suggest an 8 to $9 \mathrm{~mm}$ diameter site be required to place a $4.2 \mathrm{~mm}$ diameter implant which is often not available. To overcome this deficit bone grafting is commonly done facially to increase bone thickness up to 2 to $3 \mathrm{~mm}$ to prevent implant surface exposure and help establish gingival form (11).

For fresh extraction sites implants are sometimes placed an equivalent of $1 \mathrm{~mm}$ or more away from the facial plate, a clear demonstration of the importance of establishing adequate ring of bone support for the body of the implant particularly in the facial direction. Ring "thickness" then by implication is unstable when it becomes substantially less than $2 \mathrm{~mm}$ in thickness. The threshold for this instability may be approximately $1.7 \mathrm{~mm}$. For a $6 \mathrm{~mm}$ diameter site in which either a straight walled 4.2 diameter implant that tapers out at the neck or a $4.2 \mathrm{~mm}$ diameter implant with a $3.75 \mathrm{~mm}$ reverse conical neck are placed there is a $0.45 \mathrm{~mm}$ difference in osteotomy diameter leading to a ring of bone thickness difference of $0.23 \mathrm{~mm}$ 

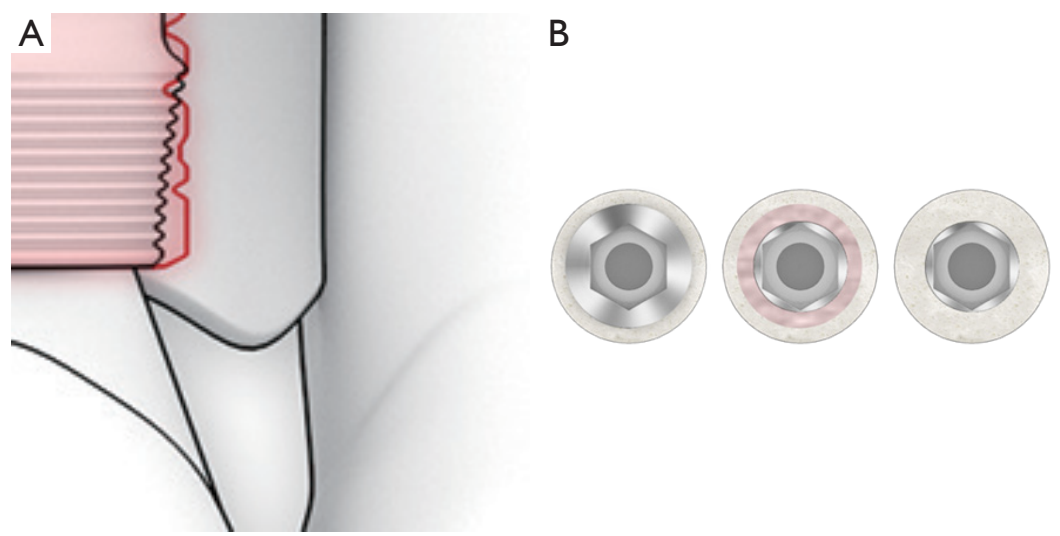

Figure 6 Schematic drawings of the titanium footprint with and without platform bone switch. (A) A lateral view of schematic drawing of a straight-wall implant in red overlaying a reverse conical neck implant illustrating the effect of the "titanium footprint" which suggests a relative thinning of the available cervical bone around the implant. (B) Figure shows a schematic of an occlusal view of a less robust volume of the ring of bone around a straight-wall implant.

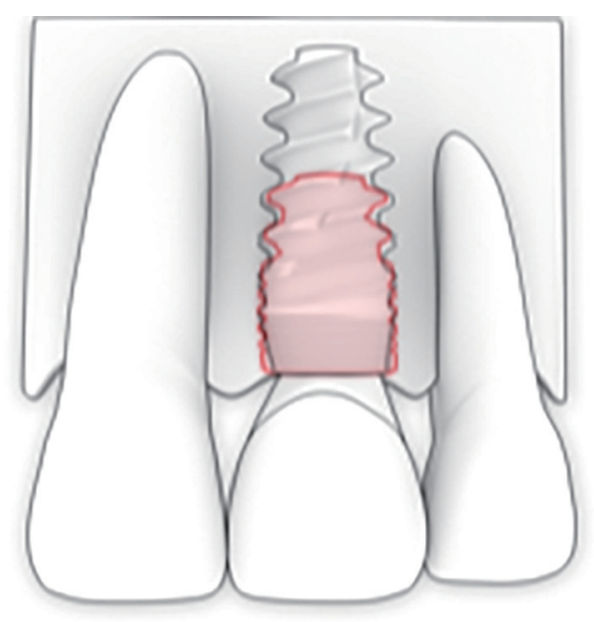

Figure 7 An overlay in red of the "titanium footprint" of a straight-wall implant onto a reverse conical neck implant to further illustrate the substantial switch-effect of combining these two bones preserving measures upon the cervical ring of bone.

circumferentially, an approximate $20 \%$ difference. This reduction in "titanium footprint" is shown schematically below in Figure $6 A$ in lateral view where the larger diameter straight walled implant is shown as a red colored overlay of the underlying reverse conical neck implant. Illustrated schematically in Figure $6 B$ is a ring of bone from an occlusal view around a straight wall implant that is relatively thin (12).

\section{Bone mass support for adjacent papilla proximate to a tooth}

Bone mass between an implant and a tooth when the implant is proximate, such as $2 \mathrm{~mm}$ away, can potentially undermine subpapillary bone. The use of platform switch in this area can displace the abutment $0.5 \mathrm{~mm}$ away from subpapillary bone leading to greater osseous support for the papilla. In addition, the platform bone switch augments this by an additional $0.23 \mathrm{~mm}$ such that $0.73 \mathrm{~mm}$ of bone is preserved in the setting of an implant proximate to a tooth. Said in another way, an implant placed two $\mathrm{mm}$ away from a tooth may actually be separated at a $2.73 \mathrm{~mm}$ distance at the cervical margin, a $37 \%$ improvement of osseous support that would not occur without platform bone switch combined with platform switch. Figure 7 shows an overlay of a straight wall implant and a reverse conical neck implant to further illustrate the substantial switch-effect of combining these two measures upon the cervical ring of bone.

At the depth (inflection point) of the reverse conical neck concavity, which is about $1 \mathrm{~mm}$ below the platform, an additional $0.3 \mathrm{~mm}$ of circumferential space is available for bone (Figure 8). This additional sum makes implant separation from the tooth root $2.57 \mathrm{~mm}$ instead of $2 \mathrm{~mm}$, a $29 \%$ improvement in bone preservation over the straight wall tapered implant design.

A clinical example by Danza et al for the use of the reverse conical neck implant next to a tooth is shown in Figures 9,10 (3). 


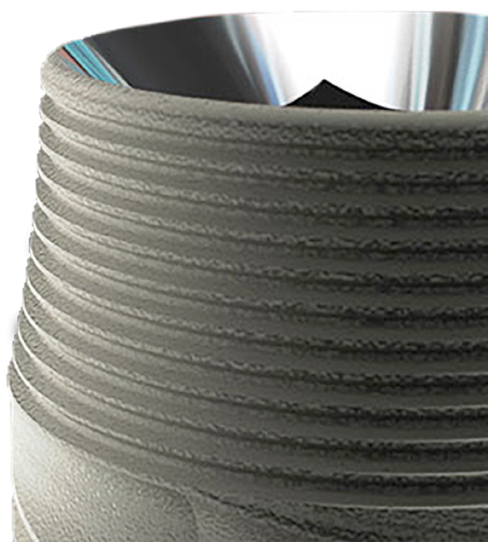

Figure 8 The reverse conical neck in itself is slightly concave with an inflection point about $1 \mathrm{~mm}$ below the implant platform which is manufactured in this way in an effort to gain additional space for bone.

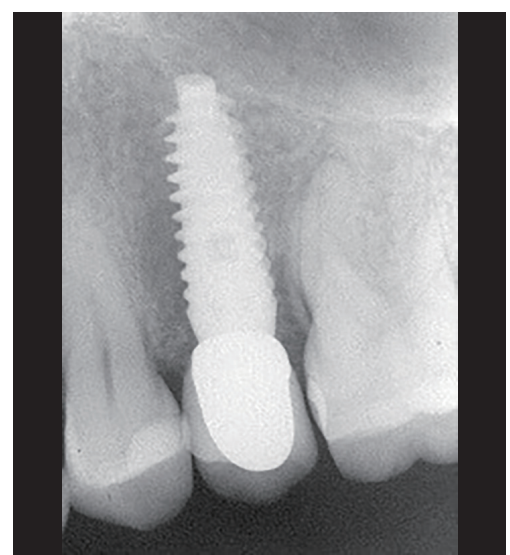

Figure 9 The peri-apical X-ray shows a clinical case in which platform bone switch is evident and bone mass increase is observed mesio-distally.

\section{Bone mass support for papilla when proximate implants}

Cervical bone mass between proximate implants that are $3 \mathrm{~mm}$ apart as is the recommendation from the literature does not greatly support a papilla (13). In fact, the use of platform switch in side-by-side implants is not a factor for the hard tissue unless the implants are placed sub-crestal. Papilla support will be modest at best and if bone is lost to a sub-platform position any papilla present could potentially become "punched out" severely compromising esthetics and self cleansability. Using the above criteria, side by side

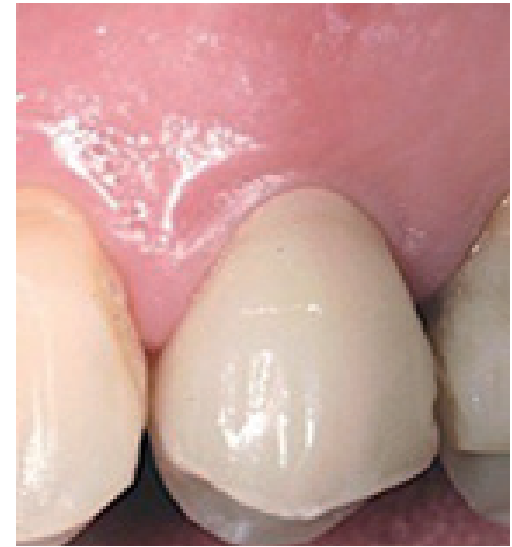

Figure 10 The platform bone switch evident on X-ray correlates clinically with abundant gingiva-papillary form as supporting subpapillary bone has grown higher than platform level both mesial and distal (Courtesy of Dr. Matteo Danza with permission).

reverse conical neck implants placed level to the crest would lead to an an addition of $0.45 \mathrm{~mm}(0.225 \mathrm{~mm}$ from each implant) between the implants or $3.45 \mathrm{~mm}$ of space-a $15 \%$ improvement in bone preservation. If implants were placed slightly sub crestal the $0.5 \mathrm{~mm}$ platform switch would be additive for a $3.95 \mathrm{~mm}$ spacing, a $32 \%$ increase in cervical bone. A clinical example of an eight-year finding of side-byside implants using the narrow neck implants is shown in Figure 11A,11B (14).

\section{Bone mass of the ring of bone}

The ring of bone concept describes the critical crestal bone at the neck of an implant in which platform bone switch and platform-abutment switch help to define the quantity of supporting cervical bone volume. When comparing a straight wall implant platform to a reverse conical neck platform, there is a significant difference at the crestal $2 \mathrm{~mm}$ of bone support in terms of bone volume preserved. Danza and Paracchini calculated the cubic volume of bone saved by the use of the reverse conical neck implant to be $5.57 \mathrm{~mm}^{3}$. This figure is per implant. This is substantial bone volume and is comprised of the narrowing of the implant neck to $3.75 \mathrm{~mm}$ from $4.2 \mathrm{~mm}$, the curved concavity of the neck itself, and the 11 cervical grooves which additionally purpose a small increase in bone volume (Figure 12). All these taken together increase viable crestal bone helping to keep bone ring thickness above the threshold where resorption becomes a greater risk to expose the titanium 

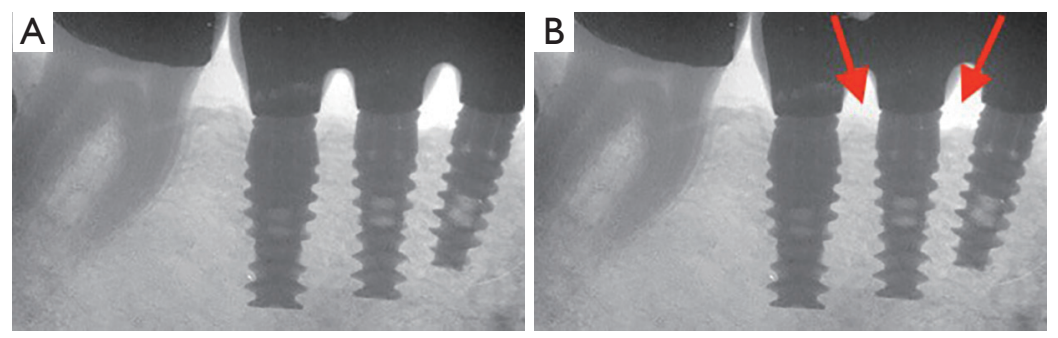

Figure 11 The two figures above (A and B) represent three side-by-side implants placed and restored 8 years prior demonstrating bone growth above the implant platforms (arrows) despite non-platform switch of the hardware. The platform bone switch demonstrates broad separation between implants approximately $3 \mathrm{~mm}$ apart which would otherwise leave implants close to $2 \mathrm{~mm}$ apart. (Courtesy of Dr. Matteo Danza with permission).

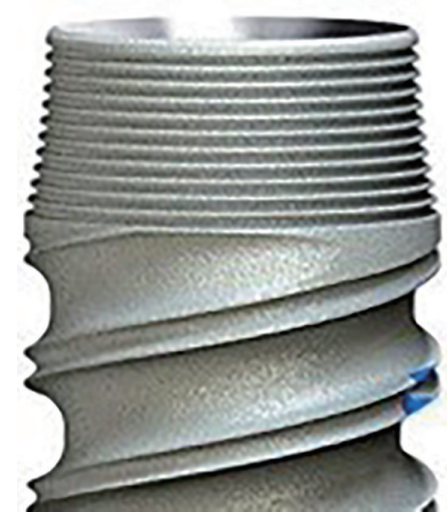

Figure 12 The reverse conical neck including its inward curved neck concavity and circumferential grooves according to Danza and Parachini who have created $5.57 \mathrm{~mm}^{3}$ of additional space for bone preservation to make the implant surface more resistant to exposure from bone resorption or peri-implant inflammatory insult.

surface to bacterial contamination. The implication is that greater bone volume may impede implant surface exposure and attendant problems associated with it as early implant surface exposure is correlated with late development of periimplantitis $(15,16)$.

Ericsson et al. described histological inflammation around two-piece implants which must be considered in any bone preservation strategy. The authors found periimplant inflammation to be of two types. One was sulcular, plaque-associated inflammation and the other deeper, at the implant abutment junction. They found histologically the zone of inflammation at the abutment junction was 1 to $1.5 \mathrm{~mm}$ leading to this potential quantity of bone loss. What platform switch is all about is displacing the abutment junction slightly away from bone to distance-effect inflammation on bone. The purpose of the platform bone switch in this regard is not as important but similar in that an attendant greater peri-implant bone mass may inhibit or retard (15-17).

\section{Abutment-implant junction}

Cervical bone preservation is supported by accurate fitting abutments such that in addition to switching to preserve bone, abutment-implant miss-fit must be considered in regard to bone loss prevention. It should be emphasized that precision fit at the abutment implant interface is very important. In fact, junction movement from misfit can completely undermine any switching bone preservation strategy. Misfit or large gap width such as seen in Figure $13 \mathrm{~A}$ leads to abutment movement and percolation of bacterial contaminates leading to the 1 to $1.5 \mathrm{~mm}$ zone of inflammation. Bacterial composition in the implantabutment connection is also affected by the precision fit and can contribute to marginal bone loss magnitude. Efforts to reduce gap size to less than .5 microns to eliminate bacterial ingress are now achievable by using aerospace engineering technology as shown here in these implant-abutment cross sections where abutment gap was measured at less than 0.5 microns which is smaller than typical constituents of oral microflora (Figure 13B-13D) (16,17).

Other factors to consider for marginal bone loss are exceptional clinical settings that may be affected by the strain rate history of bone prior to implant treatment. For example, when bone reduction is required for prosthetic reasons to increase interocclusal space, implants placed in this setting are found to subsequently lose up to $2 \mathrm{~mm}$ of peri-implant bone. This was shown in a prospective clinical trial using two different implant diameters and implant- 

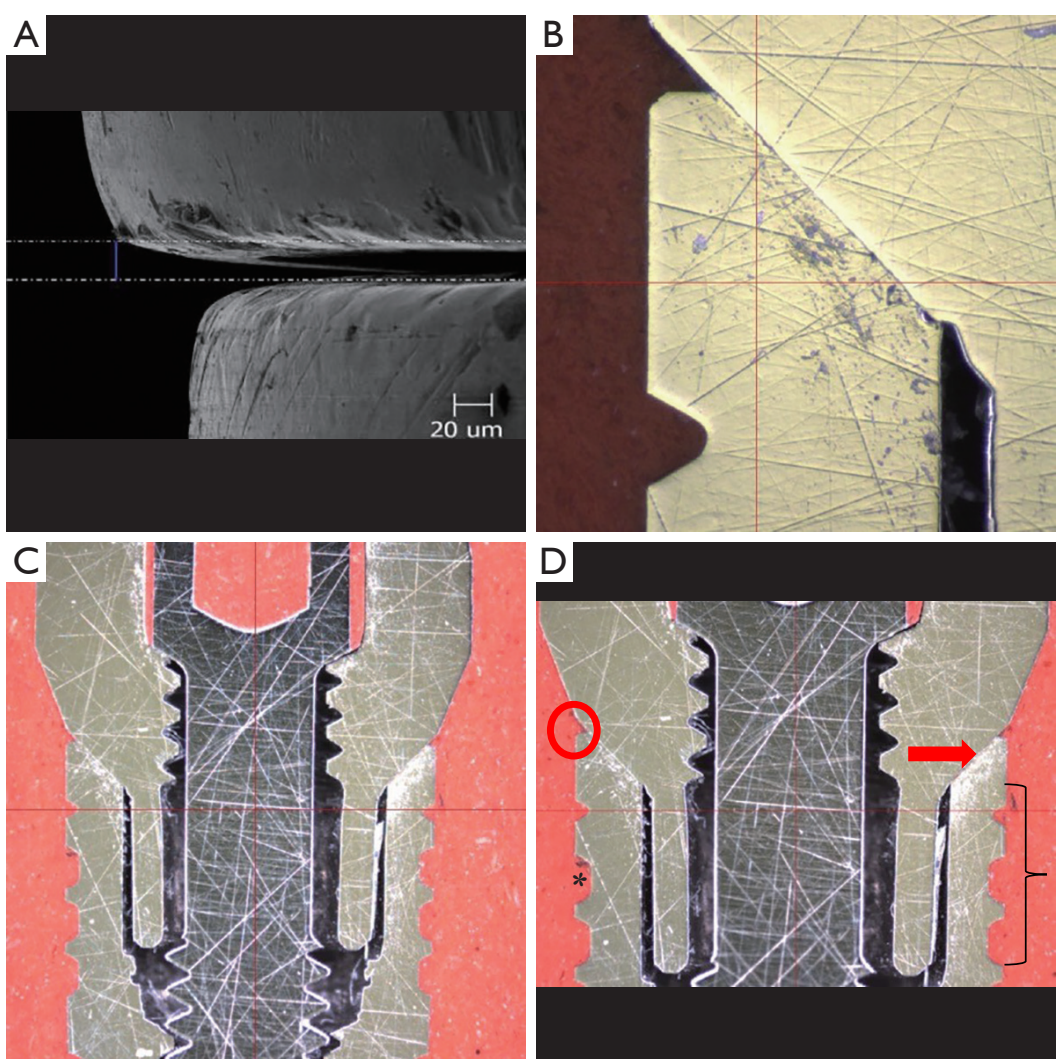

Figure 13 Implant abutment gap or "misfit" is an important phenomena that can lead to micromovement, titanium debri, bacterial percolation and bone loss. Various high resolution implant gaps are shown above. (A) An implant abutment gap exceeding 20 microns can lead to micromovement and percolation of bacterial contaminants (Courtesy of Dr. Marwan Mohamed Hendaway with permission). (B) This implant gap between abutment and implant is less than 0.5 microns making component movement in function less likely as well as bacterial ingress-egress to and from the internal confines of the implant body. (Courtesy of Ariel Zuhovitzky and Itzik Kostika Ditron Dental Ltd. Ashkelon, Israel with permission). (C) Reverse conical neck implant abutment-implant interface shows negligible gap at the internal tapered connection of less than 0.5 microns. (D) The reverse conical neck implant at the abutment-implant interface shows the following: (I) The 0.5 $\mathrm{mm}$ platform switch (circle), (II) the platform bone switch (bracket), (III) the cervical grooves (asterisk) and (IV) the precision junction of the implant-abutment connection, the gap being less than 0.5 microns (arrow). (Images for A,B,C,D are courtesy of Ariel Zuhovitsky and Itzik Kostika of Ditron Ltd. Ashkelon, Israel with permission).

abutment connections. This excessive bone remodeling finding has been described as the regional acceleratory phenomenon caused by bone damage, perhaps devitalized, from the bone reduction procedure which is additive to bone implant interface remodeling (18-21).

In another clinical study, specially designed single implants with and without platform switching on each side were evaluated up to 6 months after loading for crestal bone loss. There was no difference after 6 months though there was initially more bone resorption the first few months of healing in the non-switched side (22).

\section{Discussion}

The need for a narrow neck but a wider apical portion of an implant satisfies the dual need for biomechanical retention and preservation of bone at the crest. This is particularly important in the setting of dental extraction and immediate implant placement such as in the anterior maxilla. By having the reverse conical neck, the implant does not encroach on thin marginal bone facially while at the same time maintaining implant diameter apically increasing the possibility for primary stability for immediate temporization $(16,22)$. 

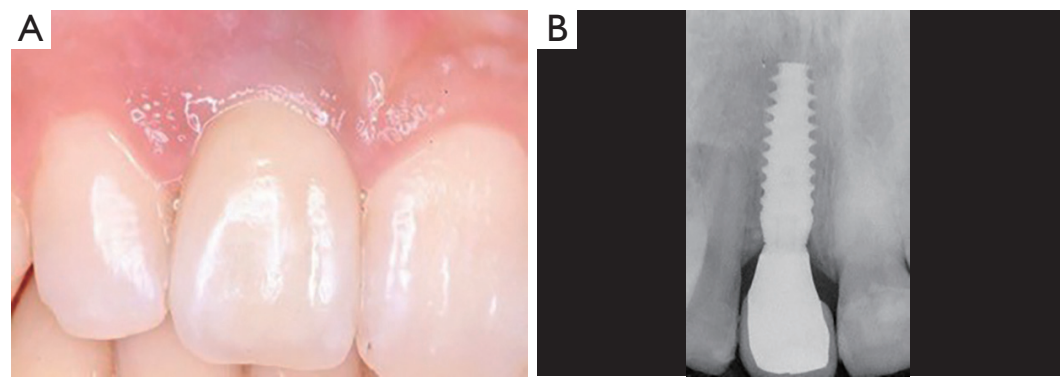

Figure 14 An anterior esthetic zone implant with a reverse conical neck leaving space for abundant bone adjacent to each proximate tooth to support soft tissue including the marginal gingiva and papillae. (A) The X-ray finding of an anterior placed implant showing a favorable platform bone switch. (B) The final restoration showing support for the marginal gingiva and papillae due to cervical ring bone support (Courtesy of Dr. Mateo Danza et al. Pescara, Italy with permission).

The design feature of the reverse conical neck of Danza has been used since 2004 and has become particularly beneficial in partially edentulous areas with narrow spaces for implants and in segmental edentulous situations where there is limited space for side-by-side implants. Instead of using narrow diameter implants to solve proximity problems a standard diameter implant can be used without adding substantial risk to marginal bone and papillary support while still maintaining needed biomechanical advantage (Figure 14A,14B) $(23,24)$.

Danza's calculation of $5.57 \mathrm{~mm}^{3}$ bone preservation for the reverse conical neck suggests that what should be considered is not maximizing titanium structural biomechanics but rather to minimize titanium footprint in deference to osseous biology when possible. And further, in order to satisfy long term implant health, to venerate the cervical ring of bone from the beginning in an effort to ward off the threat of peri-implant disease. The underpinning idea is that implant surface exposure or near exposure is the harbinger of peri-implant disease and therefore can be a clinical error if not attended to at the time of implant insertion (15).

The widely recognized benefit of the platform switch is now augmented by the platform bone switch, the two able to gain approximately $3 / 4 \mathrm{~mm}$ of addition space for bone instead of titanium. The idea and nomenclature of the platform bone switch comes from Danza et al. and has been used in published terminology since 2009. One advantage for the use of the term is that it describes a way to make room for osseous tissue by displacing unnecessary titanium- - switching" our thinking from strictly mechanical to biomechanical engineering $(6,17)$.

\section{Summary}

A tapered straight-wall implant and a reverse conical neck implant were compared at the cervical margin in terms of bone volume of the ring of bone showing long term clinical examples. The reverse conical neck implant showed a substantial difference in ring of bone volume with an increase of $5.57 \mathrm{~mm}^{3}$. These findings suggest a greater chance for maintaining adequate bone at the margin of the implant which if otherwise lost could lead to periimplantitis. The precision fit abutment-implant junction, the sub-crestal platform switch, the platform bone switch of the reverse conical neck and cervical micro-grooves all serve to increase and maintain cervical bone mass to help preserve critical marginal and subpapillary bone.

\section{Acknowledgments}

Funding: None.

\section{Footnote}

Provenance and Peer Review: This article was commissioned by the editorial office, Frontiers of Oral and Maxillofacial Medicine for the series "Current Advances in Treatment of Peri-Implantitis". The article has undergone external peer review.

Conflicts of Interest: All authors have completed the ICMJE uniform disclosure form (available at https://fomm. amegroups.com/article/view/10.21037/fomm-21-72/ coif). The series "Current Advances in Treatment of PeriImplantitis" was commissioned by the editorial office 
without any funding or sponsorship. OJ serves as an unpaid editorial board member of Frontiers of Oral and Maxillofacial Medicine and served as the unpaid Guest Editor of the series. OJ is Chairman and shareholder in Ditron Dental Implants USA LLC. GR serves as an unpaid editorial board member of Frontiers of Oral and Maxillofacial Medicine. The authors have no other conflicts of interest to declare.

Ethical Statement: The authors are accountable for all aspects of the work in ensuring that questions related to the accuracy or integrity of any part of the work are appropriately investigated and resolved.

Open Access Statement: This is an Open Access article distributed in accordance with the Creative Commons Attribution-NonCommercial-NoDerivs 4.0 International License (CC BY-NC-ND 4.0), which permits the noncommercial replication and distribution of the article with the strict proviso that no changes or edits are made and the original work is properly cited (including links to both the formal publication through the relevant DOI and the license). See: https://creativecommons.org/licenses/by-nc-nd/4.0/.

\section{References}

1. Carinci F, Brunelli G, Danza M. Platform switching and bone platform switching. J Oral Implantol 2009;35:245-50.

2. Spray JR, Black CG, Morris HF, et al. The influence of bone thickness on facial marginal bone response: stage 1 placement through stage 2 uncovering. Ann Periodontol 2000;5:119-28.

3. Danza M, Zollino I, Avantaggiato A, et al. Distance between implants has a potential impact of crestal bone resorption. Saudi Dent J 2011;23:129-33.

4. Danza M, Zollino H, Avantagiatoa A, et al. Effect of implant-tooth distance on crestal bone resorption. J Osteol Biomat 2010;(3):179-85.

5. Lazzara RJ, Porter SS. Platform switching: a new concept in implant dentistry for controlling postrestorative crestal bone levels. Int J Periodontics Restorative Dent 2006;26:9-17.

6. Danza M, Carnici F. Bone platform switching: a new concept in implantology for crestal bone preservation. European J Dent Implatologists 2008;(1):72-74.

7. Palmer RM, Floyd PD, Palmer PJ, et al. Healing of implant dehiscence defects with and without expanded polytetrafluoroethylene membranes: a controlled clinical and histological study. Clin Oral Implants Res 1994;5:98-104.

8. Zucchelli G, Felice P, Mazzotti C, et al. 5-year outcomes after coverage of soft tissue dehiscence around single implants: A prospective cohort study. Eur J Oral Implantol 2018;11:215-24.

9. Nentwig GH. Ankylos implant system: concept and clinical application. J Oral Implantol 2004;30:171-7.

10. Romanos GE, Aydin E, Gartner K, et al. Longterm results after sub crestal or crestal placement of delayed loaded implants. Clin Implant Dent Relat Res 2015;17:133-41.

11. Widmark G, Andersson B, Ivanoff CJ. Mandibular bone graft in the anterior maxilla for single-tooth implants. Presentation of surgical method. Int J Oral Maxillofac Surg 1997;26:106-9.

12. Tomasi C, Sanz M, Cecchinato D, et al. Bone dimensional variations at implants placed in fresh extraction sockets: a multilevel multivariate analysis. Clin Oral Implants Res 2010;21:30-6.

13. Zetu L, Wang HL. Management of inter-dental/interimplant papilla. J Clin Periodontol 2005;32:831-9.

14. Tarnow DP, Cho SC, Wallace SS. The effect of interimplant distance on the height of inter-implant bone crest. J Periodontol 2000;71:546-9.

15. Calvo-Guirado JL, Gómez-Moreno G, Delgado-Ruiz RA, et al. Clinical and radiographic evaluation of osseotiteexpanded platform implants related to crestal bone loss: a 10-year study. Clin Oral Implants Res 2014;25:352-8.

16. Danza M, Aollino I, Paracchini L, et al. Bone platform switching in 3D Finite element analysis comparing standard and reverse conical neck implants. EDI Journal 2008;72:2-20110.

17. Ericsson I, Persson LG, Berglundh T, et al. Different types of inflammatory reactions in peri-implant soft tissues. J Clin Periodontol 1995;22:255-61.

18. Taheri M, Akbari S, Shamshiri AR, et al. Marginal bone loss around bone-level and tissue-level implants: A systematic review and meta-analysis. Ann Anat 2020;231:151525.

19. Romanos GE, Malmstrom H, Feng C, et al. Immediately loaded platform-switched implants in the anterior mandible with fixed prostheses: a randomized, split-mouth, masked prospective trial. Clin Implant Dent Relat Res 2014;16:884-92.

20. Romanos GE, Biltucci MT, Kokaras A, et al. Bacterial Composition at the Implant-Abutment Connection under Loading in vivo. Clin Implant Dent Relat Res 
2016;18:138-45.

21. Frost HM. The regional acceleratory phenomenon: a review. Henry Ford Hosp Med J 1983;31:3-9.

22. Vandeweghe S, De Bruyn H. A within-implant comparison to evaluate the concept of platform switching: a randomised controlled trial. Eur J Oral Implantol 2012;5:253-62.

23. Atieh MA, Ibrahim HM, Atieh AH. Platform switching

doi: 10.21037/fomm-21-72

Cite this article as: Jensen O, Romanos G, Glick P. Platform bone switch to increase cervical ring bone mass. Front Oral Maxillofac Med 2023;5:18. for marginal bone preservation around dental implants: a systematic review and meta-analysis. J Periodontol 2010;81:1350-66.

24. Danza M, Palmieri A, Farinella F, et al. Three dimensional finite element analysis to detect stress distribution in spiral implants and surrounding bone. Dent Res J (Isfahan) 2009;6:59-64. 